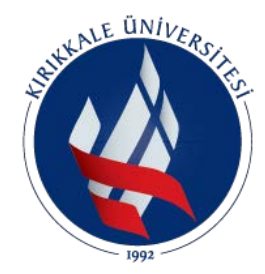

Cilt/Volume:10

International Journal of Engineering Research and Development

Sayı/Issue:2 Haziran/June 2018

https://doi.org/10.29137/umagd.402272

\title{
Vektör Otoregresyon (VAR) Modeli ile İklimsel Değișkenlerin İstatistiksel Analizi
}

\section{Statistical Analysis of Climatic Variables with Vector Autoregression Model (VAR)}

\begin{tabular}{|c|c|c|}
\hline \multicolumn{3}{|c|}{$\begin{array}{c}\text { Hayriye Esra AKYÜZ } \\
\end{array}$} \\
\hline${ }^{1}$ Bitlis Eren Üniv & Fen Edebiyat Fakültesi Ístatist & imü, 13000, Bitlis/TÜRKIYYE \\
\hline Başvuru/Received: 06/03/2018 & Kabul/Accepted: 12/05/2018 & Son Versiyon/Final Version: 29/06/2018 \\
\hline
\end{tabular}

Öz

İklimsel değişikliklerin bir sonucu olarak tüm canlılar için oldukça büyük bir tehdit oluşturan sıcaklık artışlarının belirlenmesi bu çalışmanın temel amacını oluşturmaktadır. Bu çalışmada iklimsel veriler olarak 2012-2016 yılları arasındaki ortalama basınç, minumum toprak üstü sıcaklık, ortalama nem, ortalama rüzgar hızı, ortalama sıcaklık ve toplam yağış ortalaması kullanılmıştır. İklimsel verilerin analizi için Eviews 9.0 yazılımı kullanılmıştır. Akaike Bilgi kriterine göre gecikme uzunluğu 4 olarak belirlenmiştir. Ortalama sıcaklık değiş̧kenine verilen bir standart sapmalık şokun büyük çoğunlukla kendisi ve basınç değişkeni ile belirlendiği elde edilmiştir. Sonuç olarak, ortalama sıcaklık değişkeni kısa dönemde kendi şokları ile belirlenebilmektedir. Diğer yandan 12 ayın sonunda ortalama sıcaklık değişkeninin \% 58.4'ü kendisi tarafından, \% 9.5'i ortalama minumum toprak üstü sıcaklık, \% 9.4'ü ortalama nem, \% 5.06'sı ortalama basınç ve \% 7.24'ü ortalama rüzgar hızı tarafından açıklandığı elde edilmiştir. Vektör otoregresyon modelinin, iklimsel değişkenleri modellemede başarılı olduğu belirlenmiştir.

\section{Anahtar Kelimeler}

Etki-tepki fonsiyonu, Granger nedensellik analizi, iklimsel değişken, VAR analizi

\begin{abstract}
Determination of temperature increase (global warming) as a result of climate change, became a tremendous threat for all living things, is the aim of this study. As climatic data in this study, the average of pressure, minimum temperature above soil, humudity, wind speed, temperature and total precipitation were used for the years between 2012 and 2016. Eviews 9.0 software was used to analyse the climatic data. Lag length was determined as four according to Akaike Information Criterion (AIC). It has been determined that a standard deviation shock given to the variable average temperature affects itself and the variable average pressure most. As a result, the average temperature variable is determined by its own shocks in the short term. On the other hand, at the end of 12 months, $58.4 \%$ of the variable average temperature is explained by itself, $9.5 \%$ by average minimum temperature above soil, $9.4 \%$ by average humidity, $5.06 \%$ by average pressure and $7.24 \%$ by average wind speed. It has been determined that the vector autoregression model is successful in modeling climatic variables.
\end{abstract}

\section{Key Words}

Impulse-response function, Granger casuality analysis, climatic variable, VAR analysis 


\section{GíRiș}

İklim değişikliği, iklimsel parametrelerin ortalama değerlerinde ortaya çıkan istatiksel olarak anlamlı değişimler olarak tanımlanmıştır (Türkes, 2007). İklim değişikliği günümüz araştırmacılarının en çok üzerinde durduğu konulardan biridir. Dünya iklimi, tüm jeolojik devirler boyunca sürekli bir değişim içinde olmuştur. Dünyadaki iklim değişikliklerinin en önemli göstergesi yeryüzünün yüzey sıcaklığının artışıdır. 1850'den 2007 yılına kadar yaşanan, 12 en sıcak yıldan 11 tanesi $1995-2006$ yılları arasında görülmüştür (Solomon, 2007). Literatürdeki araştırmalar iklim değişiminin Dünya'da ve özellikle Türkiye'de jeomorfolojik, hidrolojik, biyolojik ve bunlara bağlı olarak beşeri ve ekonomik etkiler bakımından oldukça önemli olduğunu göstermiştir (Bozyurt, 2002; Demirci ve Karakuyu, 2002; Ponsar vd., 2007; Önder ve Önder, 2007; Türkes, 1998). Bozyurt (2002), küresel iklim değişiklikleri üzerine bir çalışma yapmış, sanayi devrimine kadar olan iklim değişmelerinin doğal süreçler dahilinde gerçekleştiğini tespit etmiştir. Sprintall (2008), Drake Passage'da sıcaklığın uzun dönem içerisinde gösterdiği trendi ve yıllar arası değişimi incelemiştir. Shirochkov vd. (2006), Arktik bölgelerde sıcaklığın uzun zaman içerisindeki seyrini ve bunun güneş kaynaklı solar aktivitelerle ilişkisini araştırmış; solar aktivitelerin sıcaklığı etkilediği sonucuna varmışlardır. Karabulut ve Cosun (2008), yaptığı Kahramanmaraş ilinde iklim değişikliği trend analizi adlı çalışmada Mann-Kendall trend analizini kullanarak, küresel ısınmaya bağlı olarak ortaya çıkan iklim değişikliğinin bir çevre sorunu olarak Kahramanmaraş'ta ne boyutta olduğunu ortaya koymuştur. Gómez-Gesteira vd. (2009), 60 yıllık zaman süreci içerisinde Biscay Körfezi’nde deniz suyu sıcaklıklarının trendini incelemiştir. Batista vd. (2009), Rayleigh Lidar sıcaklık ölçümü yöntemi ile 35-65'inci km.lerde 14 yıllık dönemde aylık sıcaklık değerlerinin trendi üzerine bir çalışma yapmış, aylık sıcaklıkların 40 . km.de $-1.09 \pm 0.57$ Kelvin/onyıl, 50. km'de -

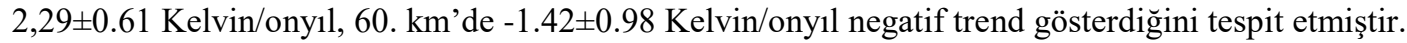

İklim değişikliklerinin Türkiye'de görülen etkilerinden dolayı sıcaklık ortalaması oldukça düşük olan Bitlis ili sınırları içerisinde, iklim değişikliğinin en önemli göstergesi olan ortalama sıcaklık ile ortalama buhar basıcı, ortalama toprak üstü minumum sıcaklık, ortalama nem, ortalama rüzgar hızı ve toplam yağış ortalaması arasındaki ilişkinin ortaya çıkarılması amaçlanmıştır. Bu bilgi ile 2012-2016 yılları arasındaki iklimsel değişkenlerin vektör otoregresyon (VAR) analizi ile modellenmesi bu çalışmanın ana konusunu oluşturmaktadır.

\section{ISTATISTIKSEL ANALIZLER}

Bu bölümde, iklimsel verilerin modellenmesinde kullanılacak olan istatistiksel analizlere yer verilmiştir.

\subsection{Birim Kök Testi}

Bir zaman serisinin birim kök içerip içermediği oldukça önemli bir kavramdır. Birim kök testleri durağanlığın sınanmasında yaygın olarak kullanılan bir yöntemdir. Zaman serisi verilerini içeren regresyon analizindeki en önemli varsayım ele elınan zaman serisinin durağan olmasıdır. Genel olarak ifade edilirse, eğer ortalaması ve varyansı zaman içerisinde sabitse ve iki dönem arasındaki kovaryans değeri bu kovaryansın hesaplandığı asıl döneme değil de sadece iki dönem arasındaki uzaklığa bağlıysa bu zaman serisi durağandır. Bu özelliklere sahip bir zaman serisi zayıf durağan olarak bilinir. Eğer zaman serisinin sadece ilk iki momenti (yani ortalama ve varyans) değil de momentlerinin tamamı zaman içerisinde değişim göstermiyorsa kesin durağandır.

$$
Y_{t}=\rho Y_{t-1}+e_{t}
$$

Burada $e_{t}$, sıfır ortalamalı ve $\sigma^{2}$ varyanslı bağımsız ve normal dağılımlı rasgele değişkenlerin bir dizisidir. Yt 'nin durağanlığının araştırılmasında kurulacak hipotezler aşağıdaki gibidir:

$$
\begin{aligned}
& H_{0}:|\rho| \geq 1 \\
& H_{0}:|\rho|<1
\end{aligned}
$$

$|\rho|<1$ ise Yt zaman serisi $\mathrm{t} \rightarrow \infty$ iken durağan bir zaman serisine yakınsar. $|\rho|=1$ ise zaman serisi durağan değildir. Dickey ve Fuller $(1979,1981)$ bir serinin durağan olmamasının nasıl formüle edilebileceği konusunda bir yöntem geliştirmişlerdir. Geliştirdikleri yöntem bir serinin durağanlığını test etmekle, seride birim kökün varlığını test etmektir.

Genişletilmiş Dickey Fuller (ADF) testinin kullanımındaki temel sorun gecikme uzunluğunun seçimidir. ADF testinin gücü ve boyut özellikleri modele dahil edilen gecikme sayısına oldukça duyarlıdır. Burada amaç otokorelasyonu ortadan kaldıracak kadar hata terimini modele dâhil etmektir. Otoregresif süreçlerde uygun gecikme sayısının belirlenmesinde kullanılan pek çok yöntem bulunmaktadır. Akaike Bilgi Kriteri (AIC), Schwart Bilgi Kriteri (SIC), Hannan Quin (HQ) ve bu üç kriterin düzeltilmiş formları bu kriterlerden bazılarıdır. Uygulamada yaygın olarak, AIC ve SIC bilgi kriterleri kullanılmaktadır. Uygun gecikmenin belirlenmesi için, AIC ve SIC bilgi kriterlerinin minimum değere sahip olması gerekmektedir. Seçilen gecikmenin gereğinden büyük olması tahminlerin eğimli olmasına yol açacaktır. Uygun gecikmenin belirlenmesi oldukça önemlidir.

\subsection{Bilgi Kriterleri}

AIC, farklı boyutlu modellerin karşılaştırmasında kullanılan güçlü bir model seçme kriteridir. Ayrıca bu kriter, bir örneklem verisinden elde edilen parametre kestirimlerinin farklı örneklemler için de kullanılmasından kaynaklanan doğruluk kaybının bir ölçümü olarak yorumlanabilir. Bu bağlamda AIC, orijinal örneklemden elde edilen parametre kestirimlerinin farklı örneklemler için çapraz-geçerliliğin bir ölçümü olarak da kullanılabilmektedir. AIC bilgi kriteri aşağıdaki gibi tanımlanır.

$$
A I C=-2 \ln (\hat{\mathrm{L}})+2 \mathrm{k}
$$


Burada $\hat{L}$, modelin olabilirlik fonksiyonunun maksimum değeri ve $k$ ise tahmin edilen parametre sayısıdır. En küçük AIC değerine sahip model en iyi modeldir. AIC sadece seçili örnek büyüklüğü içinde değil aynı zamanda seçili örnek büyüklüğü dışındaki gelecek tahmini içinde geçerlidir (Akaike, 1978).

Schwarz bilgi kriteri (SIC) ise,

$$
S I C=-2 \ln (\hat{\mathrm{L}})+\ln (\mathrm{n}) \mathrm{k}
$$

olarak ifade edilir. Burada n, gözlem sayısını belirtmektedir.

SIC, AIC'ye göre yeni değişkenlerin modele eklendiğinde ortaya çıkacak durumu değerlendirme hususunda daha dikkatli düzenlenmiştir. AIC'de olduğu gibi sadece seçili örnek büyüklüğü içinde değil aynı zamanda seçili örnek büyüklüğü dışındaki gelecek tahmini içinde geçerlidir.

\subsection{Vektör Otoregresyon (VAR) Analizi}

Sims (1980) tarafından geliştirilen model Granger nedensellik testi modelini temel alır ve modelde iki içsel değişken varsa, bunların her biri hem kendi hem de diğer içsel değişkenin belli bir döneme kadarki gecikmeli değerleri ile ilişkilendirilir. Sims, yapısal modeldeki içsel-dışsal ayırımını eleştirir. Ayrıca bu ayrımın suni olduğunu belirtir. $\mathrm{Y}_{\mathrm{t}}$ ve $\mathrm{X}_{\mathrm{t}}$ serilerini ele alacak olursak VAR modeli (Ertek, 2000: 404) aşağıdaki gibi tanımlanır.

$$
\begin{aligned}
& Y_{t}=\alpha+\sum_{j=1}^{m} \beta_{j} Y_{t-j}+\sum_{j=1}^{m} \delta_{j} X_{t-j}+\varepsilon_{1 t} \\
& X_{t}=\alpha+\sum_{j=1}^{m} \theta_{j} Y_{t-j}+\sum_{j=1}^{m} \vartheta_{j} X_{t-j}+\varepsilon_{2 t}
\end{aligned}
$$

Burada $\varepsilon_{1 t}$ ve $\varepsilon_{2 t}$ hata terimidir. Y'nin gecikmeli değerleri X değişkenini ve X'in gecikmeli değerleri Y değişkenini etkilemektedir. $\mathrm{Bu}$ modelde denklemlerin sağ tarafında yalnızca gecikmeli değişkenler yer aldığından en küçük kareler yöntemi ile bulunacak değerleri tutarlı olacaktır.

\subsubsection{Etki-tepki (impulse- response) Analizi}

VAR sistemi içinde uygun gecikme uzunlukları bulunduktan sonra etki-tepki fonksiyonları elde edilir. Etki-tepki fonksiyonları şokların değişkenler üzerindeki etkilerini ve hangi zamanda etkisinin ne olduğunu tablolar ya da grafik yardımıyla gösterimini ortaya koyar. Bu işlem ile şokların hangi değişkende meydana geldiğini ve bu şoklara değişkenlerin ne tepki vereceği anlaşlır. Şokların nasıl oluşacağını belirlemek amacıyla ilk önce değişkenlerin 10 dönem içindeki hareketleri incelenir. Serilerde meydana gelen şoklarda 1 birimlik değişim karşısında diğer serilerin verdiği tepkiler grafikler yardımıyla ortaya koyulur. Aynı sonuçlar tablo olarak da verilebilir. Sütunlar şokların meydana geldiği değişkenleri ifade ederken satırlar ise bu şoklara karşılık değişkenlerin verdiği tepkileri göstermektedir (Tarı, 2010: 465-468).

\subsubsection{Varyans Ayrıștırması Analizi}

Varyans ayrıştırması bir değişkendeki değişimin yüzde kaçı kendi, yüzde kaçınınsa diğer değişkenlerden kaynaklandığını araştırır. Varyansdaki değişimin yüzde yüze yakın bir değerini kendi başına açılıyorsa dışsal değişken olarak nitelendirilir. Bu analizde değişkenlerin sıralanması oldukça önemlidir. Sıralama dışsaldan içsele doğru yapılır. Varyans ayrıştırması VAR'da hedeflenen ikinci fonksiyondur. İncelenen değişkenlerin her birinin varyansında meydana gelen değişmenin yüzde kaçının kendi gecikmeleriyle, yüzde kaçınınsa diğer değişkenler tarafından açıklandığını araştırır. Değişkenlerin içsel ya da dışsal olup olmadıkları hakkında bir yan değerlendirme olarak da kullanılabilir (Tarı, 2006: 452-453).

\subsection{Granger Nedensellik Testi}

Granger Nedensellik tanımı "bir değişkenin geçmiş değerlerinin kullanılmasının diğer değişkenin öngörü performansını arttırması" temel fikrine dayanmaktadır. Granger (1969)'da tarafından ortaya atılan bu düşüncenin üç önemli özelliği aşağıdaki gibi verilebilir;

- Anlık nedensellik yoktur. Çünkü, bağımsız hareketler arasında daima bir zaman farkı vardır.

- Bu durumun bir sonucu olarak "eşanlı nedensellik" yoktur.

- Gelecek şimdiki zamanın nedeni olamaz. Bu tanımlama nedensel ilişkinin varlığını test etmede önemli bir role sahiptir. Ekonometride nedenselliğin en çok kullanılan işlemsel tanımı Granger (1969) çalışmasında ortaya çıkmıştır. Daha sonra Sims (1972) tarafından geliştirilmiştir.

\section{MATERYAL VE METOT}

2012-2016 dönemleri arası Bitlis iline ait ortalama sıcaklık (SIC), ortalama buhar basıcı (BAS), ortalama toprak üstü minumum sıcaklık (MSIC), ortalama nem (NEM), ortalama rüzgar hızı (RUZ) ve toplam yağış ortalaması (YAG) gibi aylık iklimsel veriler Bitlis Meteoroloji İl Müdürlüğünden gerekli izinlerin alınması sonucunda elde edilmiştir. Verilerin analizinde Eviews 9 paket programından yararlanılmıştır. İlk olarak Augmented Dickey-Fuller ve Phillips-Perron birim kök testleri ile değişkenlerin durağanlığı test edilmiştir ve değişkenler arasındaki ilişkinin sebep ve sonuçlarını ortaya çıkarmak için Granger Nedensellik testi 
uygulanmıştır. İklimsel değişkenler arasındaki ilişkinin yönü ve derecesi VAR testi ile belirlendikten sonra ortalama sıcaklığın hata varyansının, toplam varyansın yüzde ne kadarının diğer değişkenler tarafından açıklandığını belirleyebilmek için Varyans Ayrıştırması yöntemi uygulanmıştır. Bir standart sapmalık şok için sıcaklık değişkeninin verdiği tepki Etki-tepki fonksiyonları ile ölçülmüştür. Bu dönemlere ait değişkenler arasındaki nedensellik ilişkisi ortaya çıkarılarak, değişkenler VAR analizi ile modellenmiştir.

\section{BULGULAR}

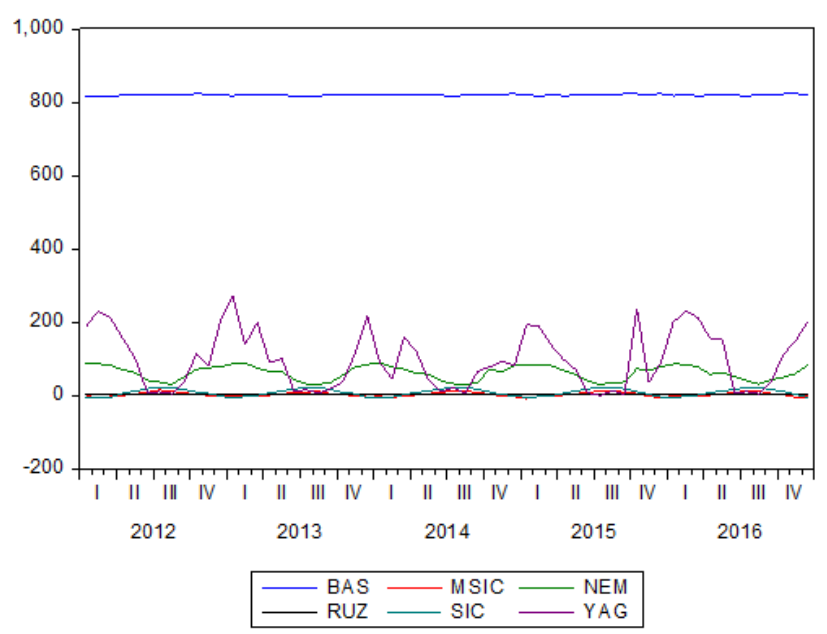

Şekil 1. Mevsimsellikten arındırılmış serilerin birlikte grafiği

Tablo 1. Birim kök testi

\begin{tabular}{|c|c|c|c|c|}
\hline & Genişletilmiş Dickey Fuller (ADF) testi & \multicolumn{2}{|c|}{ Phillips-Perron testi } \\
\hline Değişken & $\begin{array}{c}\text { Sabitli } \\
\text { model }\end{array}$ & $\begin{array}{c}\text { Sabitli ve trendli } \\
\text { model }\end{array}$ & $\begin{array}{c}\text { Sabitli } \\
\text { model }\end{array}$ & $\begin{array}{c}\text { Sabitli ve trendli } \\
\text { model }\end{array}$ \\
\hline Basınç & -6.275946 & -6.918365 & -6.321307 & -6.972070 \\
\hline $\begin{array}{c}\text { Toprak üstü min } \\
\text { sıcaklık }\end{array}$ & -6.258874 & -6.287014 & -6.257034 & -6.285335 \\
\hline Nem & -6.430907 & -6.691678 & -6.344480 & -6.621228 \\
\hline Rüzgâr & -5.955083 & -6.087898 & -5.828240 & -6.070682 \\
\hline Sıcaklık & -6.130272 & -6.177396 & -6.187907 & -6.252783 \\
\hline Yağış & -6.625899 & -6.573556 & -6.625899 & -6.573556 \\
\hline
\end{tabular}

\%1 yanılma düzeyine göre sabitli model için kritik değer -3.546; sabitli ve trendli model için -4.1213'dür.

Tablo 1'e göre tüm seriler durağandır. ADF ve Phillips-Perron testlerinin hem sabitli hem de sabitli ve trendli modellerine göre hesaplanan test istatistikleri MacKinnon (1991) tarafindan önerilen 0.01 anlamlılık düzeyindeki kritik değerlerden küçüktür. Böylelikle seriler birim kök denklemi tahmin edilememektedir. Seriler arasındaki vektörel ilişki Sims (1980) tarafindan geliştirilen Vektör Otoregresif (VAR) modeli kullanılarak tahmin edilmiştir.

Tablo 2: VAR modelinin gecikme uzunluğunun seçimi

\begin{tabular}{|c|c|c|c|c|c|}
\hline Gecikme uzunluğu & LR & FPE & AIC & SIC & HQ \\
\hline 1 & 50.40338 & $3379.601 *$ & 25.14445 & $26.67732 *$ & $25.73722 *$ \\
\hline 2 & 55.90668 & 3462.79 & 25.12243 & 27.96919 & 26.22329 \\
\hline 3 & $52.00095 *$ & 3420.723 & 24.98705 & 29.1477 & 26.59601 \\
\hline 4 & 46.03836 & 3514.646 & $24.76153 *$ & 30.23607 & 26.87858 \\
\hline 5 & 23.12729 & 7893.872 & 25.10698 & 31.89542 & 27.73212 \\
\hline \multicolumn{7}{|c}{ * Uygun gecikme uzunluğu }
\end{tabular}

Tablo 2'den görüldüğü gibi; Son kestirim hatası (FPE), Schwarz bilgi kriteri (SIC) ve Hannan-Quinn bilgi kriteri (HQ) istatistikleri uygun gecikme uzunluğunu 1 olarak, Ardışık modifiye edilmiş LR test istatistiği uygun gecikme uzunluğunu 3 ve Akaike bilgi kriteri (AIC) bilgi kriteri 4 olarak önermiş̧lerdir. Gecikme uzunluğu 1 ya da 3 olarak alındığında modelin kalıntılarında değişen varyans, serisel korelasyon ya da normal dağılmama gibi sorunlarla karşılaşılmıştır. Gecikme uzunluğu 1 alındığında; Lagrange çarpanı (LM) testi sonuçlarına göre modelin kalıntılarında 1. ve 3. gecikmede serisel korelasyon gözlenmiştir (1. gecikme için $p=0.0947<0.10$ ve 3 . gecikme için $p=0.0032<0.01)$. Gecikme uzunluğu 3 alındığında ise 1 . gecikmeye ait kalıntılarda bir serisel korelasyon gözlenmiştir $(p=0.0781<0.10)$. Böylece AIC bilgi kriterine göre modelin gecikme uzunluğu 4 olarak belirlenmiştir. VAR(4) modeli tahmin sonuçları Tablo 3'de verilmiştir. 
Tablo 3. VAR(4) modeli tahmin sonuçları

\begin{tabular}{|c|c|c|c|c|c|c|}
\hline & $\mathrm{SIC}_{\mathrm{t}}$ & MSIC $_{t}$ & $\mathbf{Y A G}_{\mathbf{t}}$ & NEM $_{\mathbf{t}}$ & BAS $_{t}$ & $\mathbf{R U Z}_{\mathbf{t}}$ \\
\hline SIC $_{t-1}$ & -0.2870 & $-0.4893 *$ & $24.5035 * * *$ & -0.4103 & $-0.4133^{* *}$ & $0.0635 *$ \\
\hline SIC $_{t-2}$ & 0.2504 & 0.4700 & -2.7215 & 1.9779* & -0.1504 & 0.0234 \\
\hline SIC $_{t-3}$ & $-0.4112 * *$ & -0.4535 & -8.6135 & 0.6317 & 0.2055 & $-0.0821 * *$ \\
\hline $\mathrm{SIC}_{\mathrm{t}-4}$ & -0.0497 & $-0.4914^{*}$ & 11.4214 & 0.1872 & -0.2731 & 0.0003 \\
\hline MSIC $_{t-1}$ & $0.3842 * *$ & $0.6996 * * *$ & 1.8598 & 1.4219* & $0.2532 *$ & $0.0690 * *$ \\
\hline MSIC $_{t-2}$ & -0.0900 & 0.2402 & -8.7735 & 0.1543 & 0.0956 & -0.0099 \\
\hline MSIC $_{t-3}$ & 0.1340 & -0.0559 & 4.5353 & -0.5500 & -0.1074 & -0.0410 \\
\hline MSIC $_{\text {t-4 }}$ & 0.1836 & 0.0174 & -6.6819 & -1.0364 & -0.0672 & -0.0131 \\
\hline $\mathbf{Y A G}_{\mathrm{t}-1}$ & -0.0064 & -0.0063 & 0.2330 & 0.0032 & -0.0043 & 0.0003 \\
\hline YAG $_{t-2}$ & 0.0019 & -0.0057 & 0.0232 & -0.0098 & 0.0042 & 0.0001 \\
\hline YAG $_{\mathrm{t}-3}$ & -0.0075 & $0.0141 * *$ & 0.2879 & 0.0336 & -0.0018 & $0.0036 * * *$ \\
\hline $\mathbf{Y A G}_{\mathrm{t}-4}$ & 0.0003 & 0.0100 & 0.1909 & $0.0735 * *$ & 0.0053 & 0.0011 \\
\hline NEM $_{t-1}$ & -0.0551 & -0.0411 & -0.4050 & -0.0702 & -0.0521 & $-0.0199 * * *$ \\
\hline NEM $_{t-2}$ & 0.0519 & -0.0909 & -0.9882 & -0.1172 & -0.0315 & -0.0035 \\
\hline NEM $_{t-3}$ & 0.0133 & -0.0698 & -1.8461 & -0.1735 & -0.0274 & -0.0088 \\
\hline NEM $_{t-4}$ & -0.0255 & -0.0734 & 2.8778 & -0.2369 & 0.0028 & $-0.0206 * * *$ \\
\hline BAS $_{\mathrm{t}-1}$ & -0.0479 & -0.3675 & -1.9720 & -0.3410 & 0.0016 & $-0.1008^{* *}$ \\
\hline BAS $_{t-2}$ & $0.3975 *$ & -0.1265 & -0.1908 & $-2.4423^{*}$ & 0.3148 & $-0.1524 * * *$ \\
\hline BAS $_{\mathrm{t}-3}$ & $-0.3943 *$ & -0.5337 & 3.4995 & 0.4955 & 0.0773 & -0.0263 \\
\hline BAS $_{\mathrm{t}-4}$ & 0.1122 & 0.2924 & 1.1972 & 1.2917 & 0.2620 & $0.0947 * *$ \\
\hline $\mathbf{R U Z}_{\mathrm{t}-1}$ & -1.4313 & $-3.5081 * *$ & -19.2643 & -8.1914 & -0.8236 & -0.0446 \\
\hline RUZ $_{t-2}$ & 1.0286 & 0.4623 & 22.6848 & 2.0428 & -0.0756 & -0.1520 \\
\hline $\mathrm{RUZ}_{\mathrm{t}-3}$ & -1.2346 & $-3.0365 * * *$ & -19.9591 & 1.1513 & 0.5691 & $-0.2941 * *$ \\
\hline RUZt-4 $_{\text {t }}$ & -0.0212 & -0.3760 & -3.0769 & 6.7233 & 0.3763 & 0.1702 \\
\hline Sabit & -37.1613 & 647.7212 & -2156.948 & 880.3866 & 293.6499 & 158.4592*** \\
\hline $\mathrm{R}^{2}$ & 0.53 & 0.55 & 0.44 & 0.45 & 0.51 & 0.73 \\
\hline$F$ & 1.48 & 1.57 & 1.01 & 1.06 & 1.36 & 3.42 \\
\hline AIC & 3.0058 & 3.7741 & 10.5992 & 6.3327 & 2.8347 & -0.3722 \\
\hline $\mathrm{SC}$ & 3.9100 & 4.6783 & 11.5033 & 7.2369 & 3.7388 & 0.5319 \\
\hline
\end{tabular}

Tablo 3'de 6 denklem için tahmin edilen katsayılar görülmektedir. Sıcaklık değişkenine ait denklemde; üç dönem gecikmeli sıcaklık değişkeninin $\left(\mathrm{SIC}_{\mathrm{t}-3}\right) 0.05$ yanılma düzeyinde negatif ve istatistiksel olarak anlamlı bir etkisi görülmektedir. Aynı denklemde, bir dönem gecikmeli toprak üstü minumum sıcaklık değişkeninin $\left(\mathrm{MSIC}_{\mathrm{t}-1}\right) 0.05$ yanılma düzeyinde pozitif ve anlamlı bir etkisi; iki dönem gecikmeli basınç değişkeninin ( $\left.\mathrm{BAS}_{\mathrm{t}-2}\right) 0.10$ yanılma düzeyinde pozitif ve anlamlı bir etkisi; üç dönem gecikmeli basınç değişkeninin $\left(\mathrm{BAS}_{\mathrm{t}-3}\right) 0.10$ yanılma düzeyinde negatif ve anlamlı bir etkisi olduğu görülmektedir. Toprak üstü minumum sıcaklık değişkenine ait denklemde; bir dönem gecikmeli sıcaklık değişkeninin $\left(\mathrm{SIC}_{\mathrm{t}-1}\right) 0.10$ yanılma düzeyinde negatif ve anlamlı bir etkisi; dört dönem gecikmeli sıcaklık değişkeninin (SICt-4) 0.10 yanılma düzeyinde negatif ve anlamlı bir etkisi; bir dönem gecikmeli toprak üstü minumum sıcaklık değişkeninin $\left(\mathrm{MSIC}_{\mathrm{t}-1}\right) 0.01$ yanılma düzeyinde pozitif ve anlamlı bir etkisi; üç dönem gecikmeli yağış değişkeninin $\left(\mathrm{YAG}_{\mathrm{t}-3}\right) 0.05$ yanılma düzeyinde pozitif ve anlamlı bir etkisi; bir dönem gecikmeli rüzgar değişkeninin $\left(\mathrm{RUZ}_{\mathrm{t}-1}\right) 0.05$ yanılma düzeyinde negatif ve anlamlı bir etkisi; üç dönem gecikmeli rüzgar değişkeninin (RUZ $\left.\mathrm{R}_{\mathrm{t}-3}\right) 0.01$ yanılma düzeyinde negatif ve anlamlı bir etkisi görülmektedir. Yağış değişkenine ait denklemde; bir dönem gecikmeli sıcaklık değişkeninin $\left(\mathrm{SIC}_{\mathrm{t}-1}\right) 0.01$ yanılma düzeyinde pozitif ve anlamlı bir etkisi görülmektedir. Nem değişkenine ait denklemde; iki dönem gecikmeli sıcaklık değişkeninin $\left(\mathrm{SIC}_{\mathrm{t}-2}\right) 0.10$ yanılma düzeyinde pozitif ve anlamlı bir etkisi; bir dönem gecikmeli toprak üstü minumum sıcaklık değişkeninin $\left(\mathrm{MSIC}_{\mathrm{t}-1}\right) 0.10$ yanılma düzeyinde pozitif ve anlamlı bir etkisi; dört dönem gecikmeli yağış değişkeninin $\left(\mathrm{YAG}_{\mathrm{t}-4}\right) 0.05$ yanılma düzeyinde pozitif ve anlamlı bir etkisi; iki dönem gecikmeli basınç değişkeninin (BAS $\left.\mathrm{B}_{\mathrm{t}-2}\right)$ 0.10 yanılma düzeyinde negatif ve anlamlı bir etkisi görülmektedir. Basınç değişkenine ait denklemde; bir dönem gecikmeli sıcaklık değişkeninin $\left(\mathrm{SIC}_{\mathrm{t}-1}\right) 0.05$ yanılma düzeyinde negatif ve anlamlı bir etkisi; bir dönem gecikmeli toprak üstü minumum sıcaklık değişkeninin $\left(\mathrm{MSIC}_{\mathrm{t}-1}\right) 0.10$ yanılma düzeyinde pozitif ve anlamlı bir etkisi görülmektedir. Rüzgar değişkenine ait denklemde ise; bir dönem gecikmeli sıcaklık değişkeninin $\left(\mathrm{SIC}_{\mathrm{t}-1}\right) 0.10$ yanılma düzeyinde pozitif ve anlamlı bir etkisi; üç dönem gecikmeli sıcaklık değişkeninin $\left(\mathrm{SIC}_{\mathrm{t}-3}\right) 0.05$ yanılma düzeyinde negatif ve anlamlı bir etkisi; bir dönem gecikmeli toprak üstü minumum sıcaklık değişkeninin $\left(\mathrm{MSIC}_{\mathrm{t}-1}\right) 0.05$ yanılma düzeyinde pozitif ve anlamlı bir etkisi; üç dönem gecikmeli yağış değişkeninin (YAG $\left.\mathrm{t}_{-3}\right) 0.01$ yanılma düzeyinde pozitif ve anlamlı bir etkisi; bir ve dört dönem gecikmeli nem değişkenlerinin $\left(\mathrm{NEM}_{\mathrm{t}-1}\right.$ ve $\mathrm{NEM}_{\mathrm{t}}$ 4) 0.01 yanılma düzeyinde negatif ve anlamlı etkileri; bir ve iki dönem gecikmeli basınç değişkenlerinin $\left(\mathrm{BAS}_{\mathrm{t}-1}\right.$ ve $\left.\mathrm{BAS}_{\mathrm{t}-2}\right)$ sırasıyla 0.05 ve 0.01 yanılma düzeylerinde negatif ve anlamlı etkileri; dört dönem gecikmeli basınç değişkeninin (BAS $\left.\mathrm{B}_{\mathrm{t}-4}\right) 0.05$ yanılma düzeyinde pozitif ve anlamlı bir etkisi ve üç dönem gecikmeli rüzgar değişkeninin (RUZ $\left.\mathrm{R}_{\mathrm{t}-3}\right) 0.05$ yanılma düzeyinde negatif ve anlamlı bir etkisi olduğu görülmektedir. 


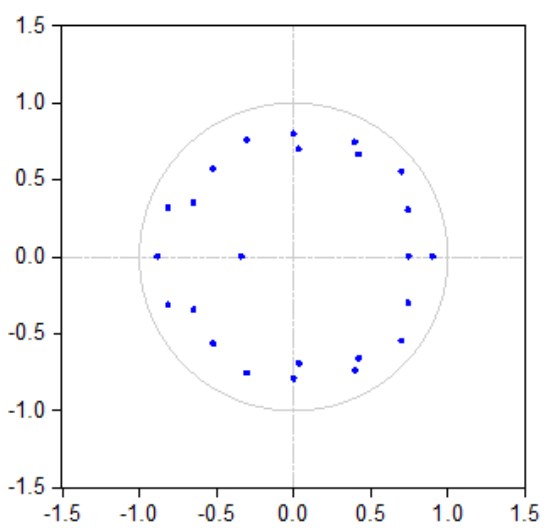

Şekil 2 . VAR modelinin istikrar grafiği

Tahmin edilen VAR(4) modelinin istikrar koşullarını sağladığı Şekil 2'de görülmektedir. Şekil 2’ye göre otoregresif karakteristik polinomunun ters kökleri birim çember içerisinde dağılmaktadır.

Tablo 4. Serisel korelasyon için LM testi

\begin{tabular}{|l|l|l|}
\hline Gecikme & LM & P değeri \\
\hline 1 & 23.03707 & 0.9537 \\
\hline 2 & 38.3966 & 0.3614 \\
\hline 3 & 39.35871 & 0.3220 \\
\hline 4 & 39.75606 & 0.3064 \\
\hline 5 & 38.70683 & 0.3484 \\
\hline 6 & 27.70772 & 0.8375 \\
\hline 7 & 42.00723 & 0.2267 \\
\hline 8 & 28.11186 & 0.8232 \\
\hline 9 & 37.34101 & 0.4073 \\
\hline 10 & 35.91287 & 0.4727 \\
\hline
\end{tabular}

Tahmin edilen VAR(4) modelinin kalıntılarında bir serisel korelasyon olup olmadığ Lagrange çarpanı (LM) testi ile test edilmiştir. Tablo 4'de görüldüğü gibi 10 gecikmeye kadar kalıntılar arasında her hangi bir serisel korelasyona rastlanmamıştır (tüm gecikmeler için $p>0.10)$.

Tablo 5. Değişen varyans ve Normallik testleri

\begin{tabular}{|c|c|c|c|}
\hline \multicolumn{3}{|c|}{ White değișen varyans testi } & \\
\hline Ki-kare & $\begin{array}{c}\text { Serbestlik } \\
\text { derecesi }\end{array}$ & $p$-değeri & \\
\hline 1029.55 & 1008 & 0.311 & \\
\hline \multicolumn{3}{|c|}{ Jarque-Bera Normallik testi } & \\
\hline Denklem & Jarque-Bera & sd & p-değeri \\
\hline 1 & 6.84 & 2 & 0.032 \\
\hline 2 & 2.94 & 2 & 0.229 \\
\hline 3 & 0.12 & 2 & 0.941 \\
\hline 4 & 1.08 & 2 & 0.581 \\
\hline 5 & 0.93 & 2 & 0.625 \\
\hline 6 & 0.70 & 2 & 0.702 \\
\hline Model & 12.63 & 12 & 0.395 \\
\hline
\end{tabular}

Tablo 5'de görüldüğü gibi, White değişen varyans testinin test istatistiği Ki-kare=1029.55 ( $p=0.311)$ olarak elde edilmiştir. $p>0.10$ olduğundan sabit varyans yokluk hipotezi reddedilemeyecektir. Her hangi bir değişen varyans sorunu bulunmamaktadır. JarqueBera test istatistiği tahmin edilen VAR(4) modeli için $12.63(p=0.395)$ olarak hesaplanmıştır. $p>0.10$ olduğundan modelin kalıntıları Normal dağılmaktadır. 
Tablo 6. VAR/Granger nedensellik analizi sonuçları

\begin{tabular}{|c|c|c|c|}
\hline Bağımlı değişken: SIC & Ki-kare & sd & $p$-değeri \\
\hline BAS & 5.35 & 4 & 0.253 \\
\hline MSIC & $11.78 * *$ & 4 & 0.019 \\
\hline NEM & 3.92 & 4 & 0.417 \\
\hline RUZ & 4.45 & 4 & 0.348 \\
\hline YAG & 5.57 & 4 & 0.234 \\
\hline Bağımlı değişken: BAS & Ki-kare & sd & $p$-değeri \\
\hline SIC & 7.06 & 4 & 0.133 \\
\hline MSIC & 4.05 & 4 & 0.400 \\
\hline NEM & 3.67 & 4 & 0.453 \\
\hline RUZ & 3.08 & 4 & 0.545 \\
\hline YAG & 2.63 & 4 & 0.622 \\
\hline Bağımlı değişken: MSIC & Ki-kare & sd & $p$-değeri \\
\hline SIC & $10.86 * *$ & 4 & 0.028 \\
\hline BAS & 4.29 & 4 & 0.368 \\
\hline NEM & 4.41 & 4 & 0.354 \\
\hline RUZ & $9.68 * *$ & 4 & 0.046 \\
\hline YAG & 6.02 & 4 & 0.197 \\
\hline Bağımlı değişken: NEM & Ki-kare & sd & $p$-değeri \\
\hline SIC & 3.96 & 4 & 0.411 \\
\hline BAS & 4.55 & 4 & 0.337 \\
\hline MSIC & 4.13 & 4 & 0.389 \\
\hline RUZ & 6.06 & 4 & 0.195 \\
\hline YAG & $8.44 *$ & 4 & 0.077 \\
\hline Bağımlı değişken: RUZ & Ki-kare & sd & $p$-değeri \\
\hline SIC & 7.06 & 4 & 0.133 \\
\hline BAS & $20.61^{* * *}$ & 4 & 0.000 \\
\hline MSIC & 6.37 & 4 & 0.173 \\
\hline NEM & $16.17 * * *$ & 4 & 0.003 \\
\hline YAG & $18.96 * * *$ & 4 & 0.001 \\
\hline Bağımlı değişken: YAG & Ki-kare & sd & $p$-değeri \\
\hline SIC & $9.39 *$ & 4 & 0.052 \\
\hline BAS & 0.15 & 4 & 0.997 \\
\hline MSIC & 3.31 & 4 & 0.508 \\
\hline NEM & 4.10 & 4 & 0.393 \\
\hline RUZ & 0.80 & 4 & 0.939 \\
\hline
\end{tabular}

*: 0.10 yanılma düzeyinde, **:0 .05 yanılma düzeyinde, ***: 0.01 yanılma düzeyinde anlamlı

Tablo 6'ya göre; toprak üstü minumum sıcaklık değişkeni sıcaklık değişkeninin nedenidir $(p=0.019<0.05)$. Sicaklık değişkeni de toprak üstü minumum sıcaklık değişkeninin nedenidir $(p=0.028<0.05)$. Böylece sicaklık ve toprak üstü minumum sicaklık değişkenleri arasında çift yönlü bir nedensellik ilişkisi bulunmaktadır. Yine tabloya göre rüzgar değişkeni toprak üstü minumum sıcaklık değişkeninin $(p=0.046<0.05)$, Yağış değişkeni nem değişkeninin $(p=0.077<0.10)$; basınç değişkeni rüzgar değişkeninin $(p=0.000<0.01)$; nem değişkeni rüzgar değişkeninin $(p=0.003<0.01)$; yağış değişkeni rüzgar değişkeninin $(p=0.001<0.01)$ ve sıcaklık değişkeni yağış değişkeninin $(p=0.052<0.10)$ nedenidir. Tüm bu sonuçlar Tablo 7'de özetlenmiştir.

Tablo 7. Nedensellik analizinin özetlenmiş sonuçları

\begin{tabular}{|l|l|l|}
\hline MSIC & $\Leftrightarrow$ & SIC \\
\hline RUZ & $\Rightarrow$ & MSIC \\
\hline YAG & $\Rightarrow$ & NEM \\
\hline BAS & $\Rightarrow$ & RUZ \\
\hline NEM & $\Rightarrow$ & RUZ \\
\hline YAG & $\Rightarrow$ & RUZ \\
\hline SIC & $\Rightarrow$ & YAG \\
\hline
\end{tabular}

$\Leftrightarrow$ : Çift yönlü nedensellik, $\Rightarrow$ : Tek yönlü nedensellik. 
Tablo 8. Sıcaklık değişkenine ait varyans ayrıştırması analizi sonuçları

\begin{tabular}{|l|c|c|c|c|c|c|}
\hline Dönem & Sicaklık & $\begin{array}{c}\text { Toprak } \\
\text { üstü } \\
\text { minumum } \\
\text { Sıcaklık }\end{array}$ & Yă̆ıŞ & Nem & Basınç & Rüzgar \\
\hline 1 & 100.00 & 0.00 & 0.00 & 0.00 & 0.00 & 0.00 \\
\hline 2 & 83.89 & 4.44 & 4.24 & 2.77 & 1.04 & 3.62 \\
\hline 3 & 72.61 & 4.69 & 5.63 & 7.30 & 5.73 & 4.04 \\
\hline 4 & 63.80 & 8.23 & 9.67 & 6.30 & 4.39 & 7.61 \\
\hline 5 & 63.68 & 8.65 & 8.95 & 7.29 & 4.14 & 7.29 \\
\hline 6 & 61.51 & 8.34 & 9.96 & 8.25 & 4.77 & 7.18 \\
\hline 7 & 59.80 & 8.97 & 10.51 & 8.84 & 4.64 & 7.24 \\
\hline 8 & 59.64 & 8.94 & 10.54 & 8.97 & 4.63 & 7.27 \\
\hline 9 & 59.36 & 9.68 & 10.22 & 9.04 & 4.64 & 7.05 \\
\hline 10 & 59.08 & 9.65 & 10.20 & 9.03 & 4.86 & 7.18 \\
\hline 11 & 58.64 & 9.58 & 10.16 & 9.34 & 5.08 & 7.20 \\
\hline 12 & 58.41 & 9.58 & 10.30 & 9.40 & 5.06 & 7.24 \\
\hline
\end{tabular}

Tablo 8'de görülebileceği gibi, sıcaklık değişkeni kısa dönemde kendi şoklarınca belirlenmektedir. 12 ayın sonunda sıcaklık değişkeninin \%58.41'i kendisi tarafından, \%9.58'i toprak üstü minumum sıcaklık, \%10.3'ü yağış, \%9.4'ü nem, \%5.06'sı basınç ve \%7.24'ü rüzgar değişkeni tarafından açıklanmaktadır. Sıcaklık değişkenine ait varyans ayrıştırma sonuçları Şekil 4'de de görülebilir.

Response to Generalized One S.D. Innovations \pm 2 S.E.
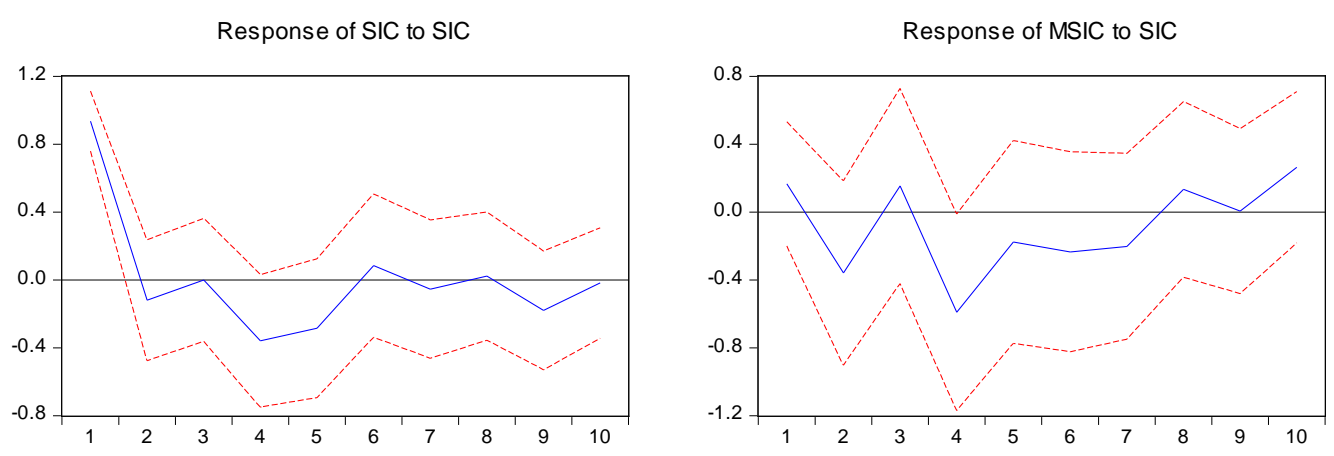

Response of YAG to SIC
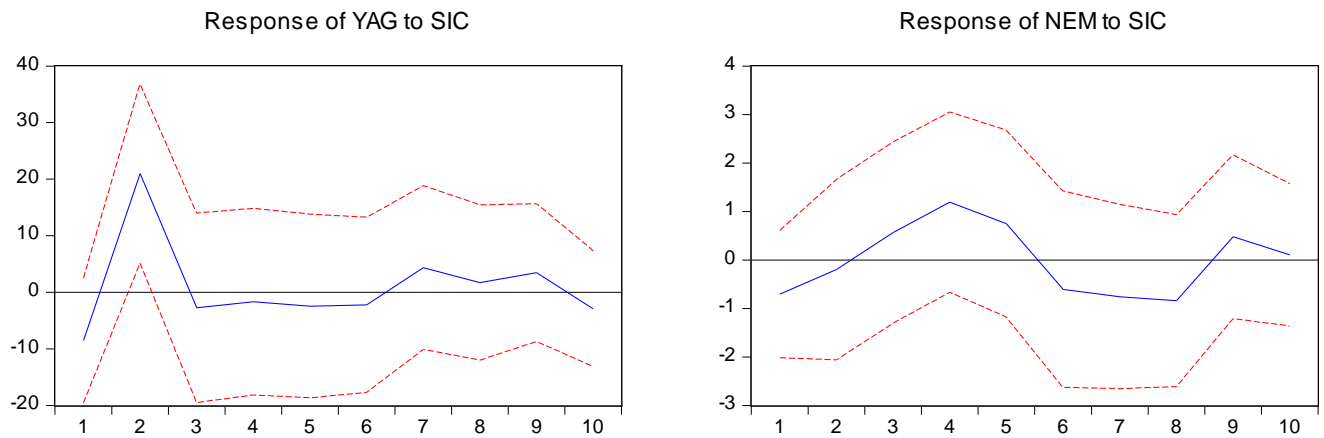

Response of RUZ to SIC
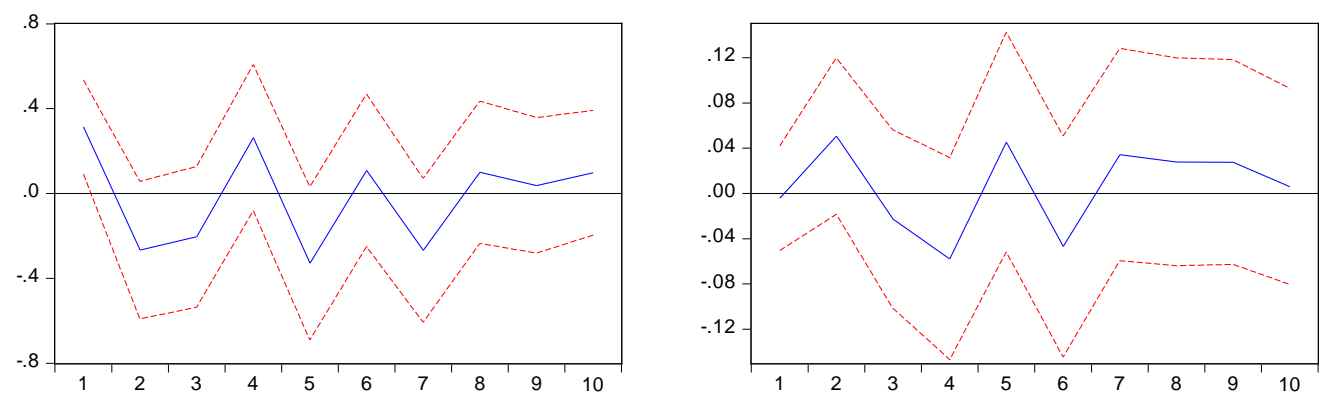

Şekil 3. Sıcaklık değişkenine verilen bir şokun diğer seriler üzerindeki etkileri 
Şekil 3'de görüldüğü gibi; sıcaklık değişkenine verilen bir standart sapmalık şok kendisini iki dönem pozitif etkilemekte, daha sonraki dönemlerde negatif etkilemektedir. Bu etki altı dönem sonra azalarak kaybolmaktadır. Sicaklık değişkenine verilen bir standart sapmalık şok toprak üstü minumum sıcaklık değişkenini ilk dönem pozitif, ikinci dönem negatif, üçüncü dönem pozitif ve diğer dönemler negatif etkileyerek kaybolmaktadır. Sıcaklık değişkenine verilen bir standart sapmalık şok yağış değişkenini ilk dönem negatif, ikinci dönem pozitif etkilemekte ve şokun etkisi üçüncü dönemden sonra kaybolmaktadır. Sıcaklık değişkenine verilen bir standart sapmalık şok nem değişkenini ilk iki dönem negatif; üç, dört ve beşinci dönem pozitif etkilemekte daha sonraki dönemlerde negatif etkileyerek kaybolmaktadır. Sıcaklık değişkenine verilen bir standart sapmalık şok basınç değişkenini ilk dönem pozitif, iki ve üçüncü dönem negatif sonraki dönemler sırayla pozitif ve negatif etkileyerek kaybolmaktadır. Sıcaklık değişkenine verilen bir standart sapmalık şok rüzgâr değişkenini ilk dönem etkilememekte, ikinci dönem pozitif, üçüncü ve dördüncü dönem negatif etkileyerek kaybolmaktadır. Genel olarak değerlendirildiğinde sıcaklık değişkenine verilen bir standart sapmalık şok en çok kendisini ve basınç değişkenini etkilemektedir.

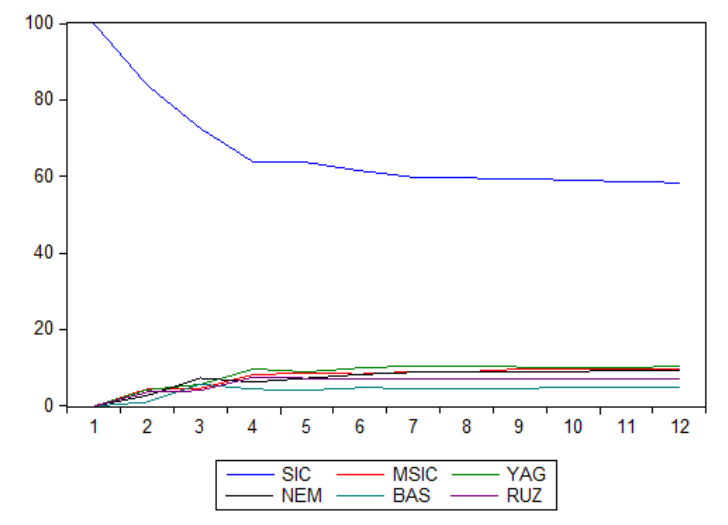

Şekil 9. Sicaklık değişkenine ait varyans ayrıştırma grafiği

Şekil 9, Tablo 8'deki varyans ayrıştırma sonuçlarının yani değişkenlerin beraberce yüzdesel değişimlerinin birlikte grafiğidir. Tabloya baktığımızda nem değişkenindeki değişkenliğin çoğu 12 dönem boyunca en çok toprak üstü minumum sıcaklık değişkeni tarafından açıklanmaktadır. Bu sonuç grafikte de görülmektedir. Grafikteki en üstteki nem serisine en yakın seri toprak üstü minumum sıcaklık serisidir. Böylelikle varyans ayrıştırma grafiği, ilgili değişkenin çizgisine en yakın çizgilere bakılarak ilgili değişkenin en çok hangi seriler tarafından dönemler boyunca açıklandığı hakkında bilgi verir.

\section{SONUÇ}

Vektör otoregresyon modeli değişkenlerin durağanlığını gerektirir. Çalışmada ele alınan ortalama sıcaklık, ortalama buhar basıcı, ortalama toprak üstü minumum sıcaklık, ortalama nem, ortalama rüzgar hızı ve toplam yağış ortalaması serileri durağandır. AIC bilgi kriterine göre modelin gecikme uzunluğu 4 olarak belirlenmiştir. Bu bilgi ile VAR (4) ile modeline ait katsayılar elde edilerek mevcut model oluşturulmuştur. Ayrıca tahmin edilen VAR(4) modelinin istikrar koşullarını sağladığı ve 10 gecikmeye kadar kalıntılar arasında her hangi bir serisel korelasyona rastlanmadığı görülmüştür. Çalışmada kullanılan seriler arasındaki değişen varyans sorunu White değişen varyans testi ile incelenmiş ve böyle bir problemin olmadığına karar verilmiştir. Granger nedensellik analizi sonucunda ortalama toprak üstü minumum sıcaklık ile ortalama sıcaklık arasında çift yönlü bir nedensellik bulunurken diğer seriler arasında tek yönlü bir nedensellik olduğu belirlenmiştir. Varyans ayrıştırması sonucunda sıcaklık değişkeni kısa dönemde kendi şoklarınca belirlenebildiği elde edilmiştir. Sıcaklık değişkenine verilen bir standart sapmalık şokun en çok kendisini ve basınç değişkenini etkilediği belirlenmiştir.

\section{KAYNAKLAR}

Akaike, H. (1978). On the likelihood of a time series model. The Statistician, 217-235.

Batista, P. P., Clemesha, B. R., \& Simonich, D. M. (2009). A 14-year monthly climatology and trend in the 35-65 km altitude range from Rayleigh Lidar temperature measurements at a low latitude station. Journal of Atmospheric and Solar-Terrestrial Physics, 71(13), 1456-1462.

Bozyurt, O. (2002). Küresel iklim değişiklikleri. 11-13 Nisan Klimatoloji Çalıştayı Bidiriler Kitabı, 247-256.

Demirci, A., \& Karakuyu, M. (2002). Küresel iklim değişimi ve Türkiye’nin fiziki ve beşeri coğrafyası üzerindeki olası etkileri. Klimatoloji Çalıştayı, İzmir, 235-245.

Dickey, D. A. \& Fuller, W. A. 1979. Distrubition of the estimators for autogressive time series with unit root. Journal of the American Statistical Association, 74, 427-431. 
Dickey, D. A. \&Fuller, W. A. 1981. Likilihood ratio statistics for autoregressive time series with a unit root, Econometrica, 49(4), 1057-1072.

Ertek, T. (2000). Ekonometriye Giriş. İstanbul: Beta Yayıncılık, 2. Baskı.

Gómez-Gesteira, M., Alvarez, I., \& Gesteira, J. L. G. (2009). Present warming within the context of cooling-warming cycles observed since 1854 in the Bay of Biscay. Continental Shelf Research, 29(8), 1053-1059.

Granger, C.W. (1969). Investigating causal relations by econometric models and cross-spectral methods. Econometrica: Journal of the Econometric Society, 424-438.

Karabulut, M., \& Cosun, F. (2009). Kahramanmaraş ilinde yağışların trend analizi. Coğrafi Bilimler Dergisi, 7(1), 65-83.

MacKinnon, J. G. (1991). Critical Value for Cointegration Tests in Advanced Texts in Econometrics.

Önder, S., \& Önder, D. (2007, March). Evaluation of water resources on the basis of river basins and the probable changes to occur in basin management in the future due to global climate change. In International Congress: River Basin Management(Vol. 1, pp. 22-24).

Ponsar, S., Ozer, J., \& Van den Eynde, D. (2007). Impacts of climate change on the physical and chemical parameters of the North Sea (literature study). Management Unit of the North Sea Mathematical Models, Brussels.

Sims, C. A. (1972). Money, income, and causality. The American economic review, 540-552.

Sims, C. A. (1980). Macroeconomics and reality. Econometrica: Journal of the Econometric Society, 1-48.

Solomon, S. (Ed.). (2007). Climate change 2007-the physical science basis: Working group I contribution to the fourth assessment report of the IPCC (Vol. 4). Cambridge university press.

Sprintall, J. (2008). Long-term trends and interannual variability of temperature in Drake Passage. Progress in Oceanography, 77(4), 316-330.

Tarı, R. (2006). Ekonometri. İstanbul: Avcı Ofset, 4. Baskı.

Tarı, R. (2010). Ekonometri. Kocaeli: Umuttepe Yayınları, Genişletilmiş 6. Baskı.

Türkes, M. (1998). Influence of geopotential heights, cyclone frequency and Southern Oscillation on rainfall variations in Turkey. International Journal of Climatology, 18(6), 649-680.

Türkeş, M. (2012). Türkiye'de gözlenen ve öngörülen iklim değişikliği, kuraklık ve çölleşme. Ankara Üniversitesi Çevrebilimleri Dergisi, 4(2), 1-32. 